\title{
Discussing the genesis of karst rocky desertification research based on the correlations between cropland and settlements in typical peak-cluster depressions
}

\author{
Yang Bing $\mathrm{Li}^{1}$, Qiong Yao $\mathrm{Li}^{2}$, Guang Jie Luo ${ }^{3}$, Xiao Yong Bai ${ }^{3}$, Yong Yan Wang ${ }^{4}$, Shi Jie Wang ${ }^{3}$, Jing Xie ${ }^{1}$, and \\ Guang Bin Yang ${ }^{1}$ \\ ${ }^{1}$ School of Geography and Environmental Sciences, Guizhou Normal University, Guiyang 550001, China \\ ${ }^{2}$ College of Geographical and Tourism, Chongqing Normal University, Chongqing 400047, China \\ ${ }^{3}$ National Key Laboratory of Environmental Geochemistry, Geochemistry Institute, Chinese Academy \\ of Sciences, Guiyang 550002, China \\ ${ }^{4}$ Laboratory of Mountain Surface Processes and Ecological Regulation, Institute of Mountain Hazards and \\ Environment, Chinese Academy of Sciences, Chengdu, Sichuan 610041, China
}

Correspondence to: Y. B. Li (li-yapin@sohu.com)

Received: 22 January 2016 - Published in Solid Earth Discuss.: 18 February 2016

Revised: 31 March 2016 - Accepted: 1 April 2016 - Published: 9 May 2016

\begin{abstract}
This paper attempts to explain the theoretical reasons why local farmers have executed land mismanagement measures such as steep slope land cultivation, in order to reveal the mechanisms of karst rocky desertification (KRD, including light KRD, moderate KRD and severe KRD) through typical case studies. Firstly, this paper assumes that the low land capacity is the initial cause of KRD in peak-cluster depression areas. Furthermore, the ecological quality of the peak-cluster depression zone (a combination of clustered karst cones with a common base and depressions between cones) is influenced by the relationship between the area of depressions and the population of residential areas. Therefore, six typical peak-cluster depression areas of Guizhou province were selected to compare the distribution circumstances of cropland, the characteristics of settlements and the formation of KRD with the help of ALOS images in 2010 (with a resolution of $10 \mathrm{~m} \times 10 \mathrm{~m}$ ). The results show that there is a negative correlation between the percentage of the cultivated land and the percentage of KRD at peak-cluster depressions. The relationship could be concluded by three situations of the process of KRD, which are low, middle and upper carrying capacities of land. Severe KRD is only distributed in peak-cluster depression areas with less flatland, low land capacity and a high population. The harmonization between population pressure and bearing capacity of land
\end{abstract}

will influence the ecological qualities in the peak-cluster depressions. The KRD phenomenon which occurred in six typical peak-cluster depression areas confirms that the hypothesis suggested by this paper is correct, and this result will contribute to understanding the natural mechanisms of KRD and guide the ecological restoration of KRD land.

\section{Introduction}

Karst is a type of eco-environment that is quite vulnerable (Gams, 1993; Sauro, 1993; Praiser and Pascali, 2003; North et al., 2009; Gabrovšek et al., 2011; Guo et al., 2013). The "classic" karst area in Europe is traditionally known as a bare, non-forested stony grassland area which suffers from severe deforestation, erosion and near desertification (Gams, 1993; Bou, et al., 2008). However, an almost treeless stony grassland landscape on the classic karst was converted to a forest-dominated landscape in only 250 years (Kaligarič and Ivanjnšič, 2014). In the karst areas of southwestern China, carbonate rocks cover about $42.6 \times 10^{4} \mathrm{~km}^{2}$, largely in the province of Guizhou, Guangxi Zhuang Autonomous Region and the province of Yunnan (Wang, et al., 2004a). In karst mountainous areas in Southwest China, there is long-term irrational land use, leading to intense erosion and vegeta- 
tion degradation, namely karst rocky desertification (KRD), which has become a hot topic. The Chinese government has begun to pay attention to it because of its importance in recent years (Jiang et al., 2014). Peak-cluster depression areas are one of the most typical types of karst topography and experience the most serious KRD processes (Jiang et al., 2007). A composite nature of degenerative conditions is formed in this area where a fragile ecological environment is the basis, human disturbance is the strong driving force and the vegetation decline and land productivity degradation is the result (Peng et al., 2011). All these factors make KRD the most difficult process to control (Li et al., 2005).

Desertification is defined as land degradation in arid, semiarid and dry subhumid areas, resulting from various factors, including climate variation and human activities (UNCCD, 1994), and has been recognized as an integrated environmental development problem that has combined a natural and social cause-effect cycle for several decades (Bisaro et al., 2014; Torres et al., 2015). Desertification does not involve only arid lands, is not necessarily irreversible and does not necessarily lead to a desert landscape (Le Houérou, 2009). Therefore, even in tropical areas, there is a risk of desertification (Izzo et al., 2013), and desertification is now considered the result of a long-term failure to balance and protect ecosystems' services (Bisaro et al., 2014). Desertification as land degradation has usually occurred in the northern and western parts of China; therefore, when some Chinese scholars refer to desertification, they do not state explicitly whether Chinese desertification includes karst rocky desertification (KRD) in Southwest China (Miao et al., 2015; Wang et al., 2015).

KRD refers to the degradation process of desert-like landscapes with severe soil erosion, and a severe decline in land productivity under the fragile subtropical karst environment damaged by irrational social and economic human activities (Wang et al., 2004a). It refers to the changing processes which transform a karst area that was covered by vegetation and soil into a rocky landscape almost devoid of soil and vegetation also (Yuan, 1997). The dynamic geological process (Zhang et al., 2001), the effect of lithology (Wang et al., 2004b) and meteorological factors (Xiong et al., 2009) upon KRD are emphasized when some scholars explain the causes of KRD. Population, arable land per capita and farmers' concept of the human-land relationship could explain $79.0 \%$ of the environmental pressure measured by the area of KRD (Wu et al., 2011) and more than half of total KRD dominated in areas within $4 \mathrm{~km}$ of the rural settlement (Jiang et al., 2009).

The KRD phenomenon in karstic mountains in Southwest China is the result of physical and human factors. The motives for researching this phenomenon are the land mismanagement, the cropland per capita and the rural settlements. $\mathrm{KRD}$ is related to different types of land use, and a great number of sloping cropland is still the main driving force of KRD ( $\mathrm{Li}$ et al., 2009). The reasons why farmers have re- claimed overly sloping land, thereby inducing severe KRD, are attributed to the macro socioeconomic circumstances of the rural locality (Yan and Cai, 2015). However, to date the formation and development of KRD has not been linked to cropland resources, settlement population and their related ecological impacts. It also does not reveal why the karst mountain farmers persist in unsustainable land management practices, and explain why the KRD occurred in karst land. Therefore, the aim of the work is as follows:

1. to understand the characteristics of flat cropland distributed at different karst topography and combined patterns

2. to understand the relationship between farmland resources, settlement patterns and the mechanisms of KRD taking place in karst mountains.

\section{Material and methods}

\subsection{The study area}

In the typical karst area covering basically the natural and socioeconomic backgrounds in the southwest karst region of China, we selected a total of six areas - the town of Beipanjiang in the county of Zhenfeng, the town of Pingle in the county of Anlong, Wangjiazhai small watershed in the city of Qingzhen, Houzhaihe in the county of Puding and the town of Dongtang in the county of Libo in Guizhou - as the study area (Fig. 1). These areas have different topography and combined patterns of land resources, including (1) peak-cluster depressions-canyon; (2) continuous closed peak-cluster depression group; (3) peak-cluster depression-valley combination; (4) open peak-cluster depressions; (5) peak-cluster depressions surrounded by flatland and shallow-peak-cluster depression (Fig. 1). The socioeconomic factors of these six study areas include different types of economic development and road accessibilities that are quite different. The Wangjiazhai is adjacent to the city, and its development is driven by the city. The Houzhaihe area is influenced by the county and town's economic radiation, Huajiang area's development is driven by the poverty-alleviating and KRD control policy and Dongtang is influenced by the national nature reserve. Pingle is in the karst mountain hinterland which is away from town traffic trunk roads, resulting in an area with slow development.

\subsection{Data sources and methods}

The land use data used in the study, including data on settlements and cropland, come from the interpretation of Advanced Land Observation Satellite (ALOS) images (with a resolution of $10 \mathrm{~m} \times 10 \mathrm{~m}$ ) in 2010 , combined with local agricultural statistics, field surveys distinguishing the characteristics of land use and KRD in 2011 and 2012 and $2.5 \mathrm{~m}$ supplementary images (with a resolution of $2.5 \mathrm{~m} \times 2.5 \mathrm{~m}$ ). 


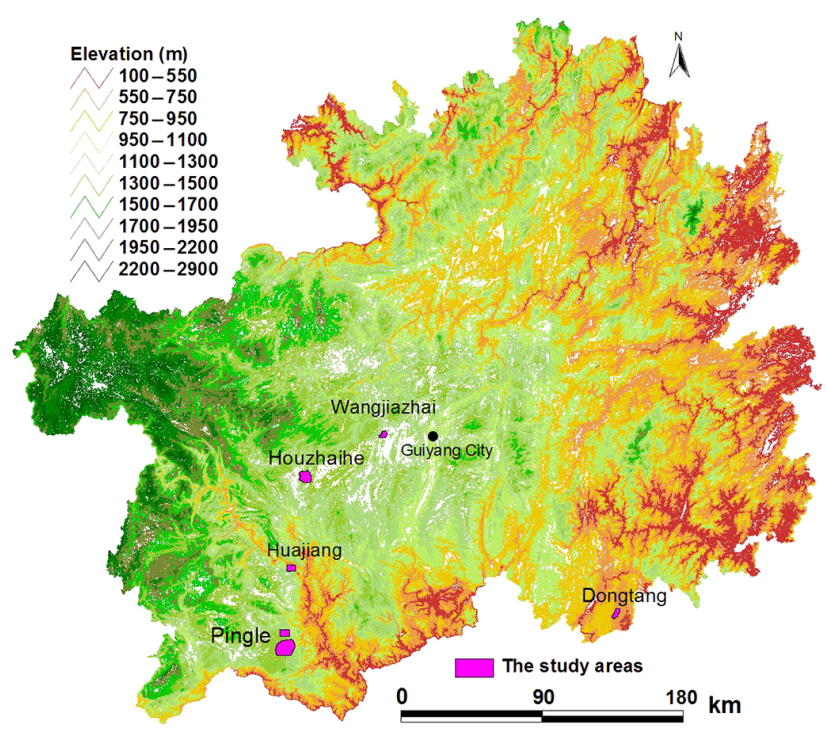

Figure 1. Distribution of the study areas.

The land use/cover types were divided into seven subclasses such as cropland, settlement, road, water, slope cropland, woodland and shrub grassland, by integrating the national standardized land classification scheme and the land use types of the local area. In this paper KRD classification criteria are described in Fig. 2, based on other researchers' work (Huang and Cai, 2007; Yue et al., 2010; Xu et al., 2013; Zhang et al., 2014). The NKRD (no karst rocky desertification) refers to the concentrated and contiguous woodland and the flatland with no land degradation, the PKRD (potential karst rocky desertification) refers to the karst sloping land where the land ecosystem has been degraded slightly, but the percentage of bare rock is less than $30 \%$ and the sloping cropland, shrub grassland may be in a land degradation state of LKRD (light karst rocky desertification), MKRD (moderate karst rocky desertification) or SKRD (severe karst rocky desertification). The distribution maps of land use and KRD land in six study areas were made using a the humancomputer interactive interpreting method, and the vector data layers were amended according to the result of the field sampling inspection and investigation in 2010; the interpretation accuracy of sampling patches is more than $90 \%$. The topography, land use and KRD of these study areas are provided by Fig. 2 . The slope gradient is generated by a digital elevation model, digitized according to the topographic map at a $1: 10000$ scale.

Because the sloping cropland is still the main driving force of KRD ( $\mathrm{Li}$ et al., 2015), farmland referred to in this paper is only that with a slope $<6^{\circ}$; the area of flat cropland with a slope $<6^{\circ}$ is used to represent land carrying capacity. The ratio of settlements area to the cropland area is used to represent population pressure, for which both data were acquired from ALOS image interpretation. The local agricul- tural statistics are used to verify the area of flat cropland and slope cropland further.

We consider assessing the land carrying capacity of six study sites according to the area and the spatial distribution of cropland patches. First, if the percentage of arable land resources of the total area is less than $10 \%$, we consider the study area to have a lack of arable land resources; if not, the study area is rich in land resources. Second, in order to further illustrate the spatial distribution of agglomeration and the fragmentation characteristics of cropland patches at six study sites, we divide the area of cropland patches into eight levels: 1 . $\leq 0.1 ; 2$. 0.1-1; 3. 1-5; 4. 5-10; 5. 10-20; 6. 20$50 ; 7.50-100 ; 8 .>100 \mathrm{hm}^{-2}$, and count the total number and total area of cropland patches of different size levels. Aggregation refers to the tendency of patch types to be spatially aggregated, so, the aggregation index of cropland patches was computed using FRAGSTATS 4.2. For the definitions and full descriptions of these metrics, please see FRAGSTATS 4.2 user's guide.

\section{Results and analysis}

\subsection{Distribution of cropland resources}

In the karst peak-cluster depression area, different combinations of small terrain have different proportions of flatland terrain (referred to as depressions in this paper) and form different area proportions of cropland resources. For the six study areas, the flat cropland area is the least at the peak-cluster canyon, in which small and scattered cropland patches are distributed. The area percentage of cropland at the peak-cluster depression-valley combination increases to $10.74 \%$, and this percentage at peak-cluster depression surrounded by shallow hills area is the highest (Table 1). In terms of the percentage of cropland resources accounting to total area, six study areas can be divided into three types. The continuous deep depressions, shallow depressions and peak-cluster canyon show a shortage of cropland resources; open peak-cluster depression and peak-cluster depression surrounded by shallow hills are comparatively rich in cropland resources and peak-cluster depression-valley is the transitional one between plenty and scanty cropland resources.

The most frequent size of croplands ranges from the groups $<0.1$ to $0.1-1 \mathrm{hm}^{2}$; there are only 17 cropland patches $20 \mathrm{hm}^{2}$ and the total area of these 17 patches accounts for $67 \%$ of the total cropland area in the peak-cluster depression-valley combination (Fig. 3). This indicates that the cropland is relatively concentrated and contiguous in this kind of landform with characteristics of big patches located in valleys and larger depressions, while small patches are located in small depression centers.

The number of croplands from $0.1-1$ to $1-5 \mathrm{hm}^{2}$ are 162 and 39 , and their areas account for 28.24 and $36.12 \%$ of the total cropland area respectively; there are only two patches 

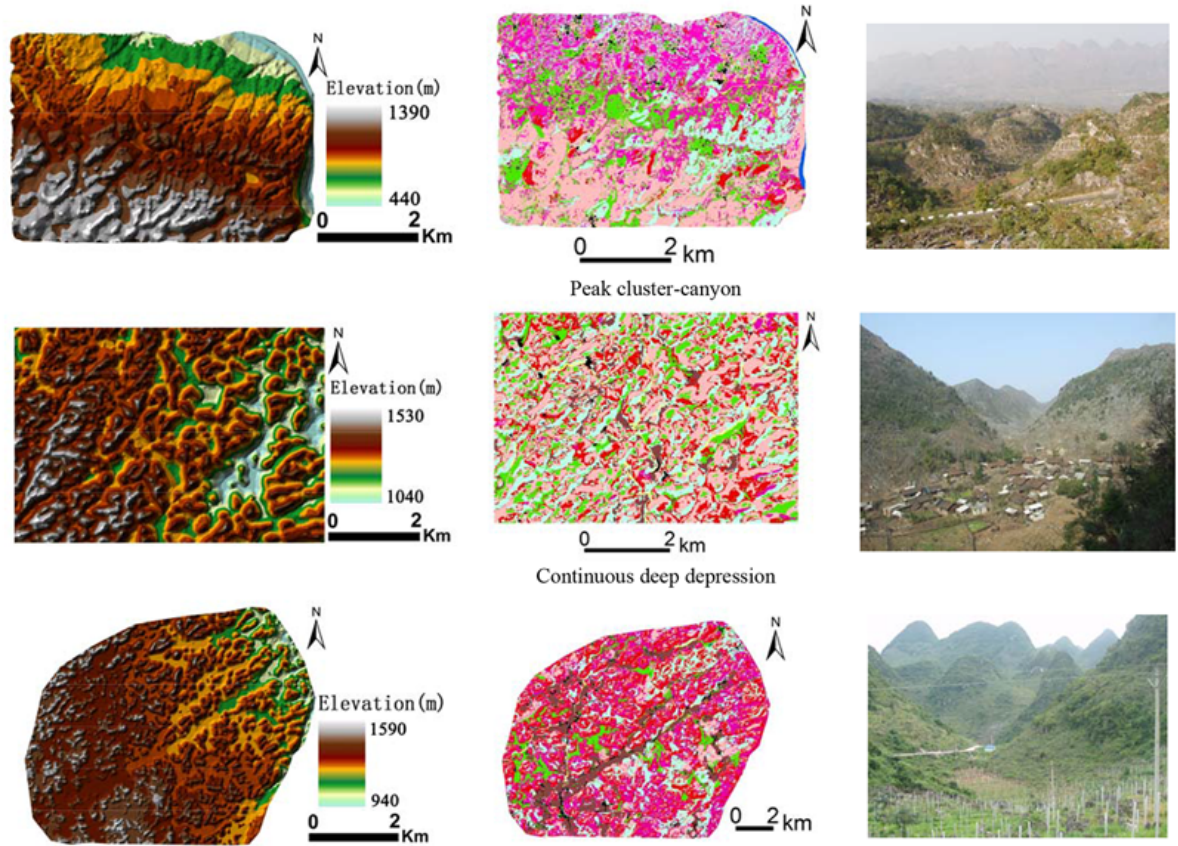

Peak cluster depression-valley
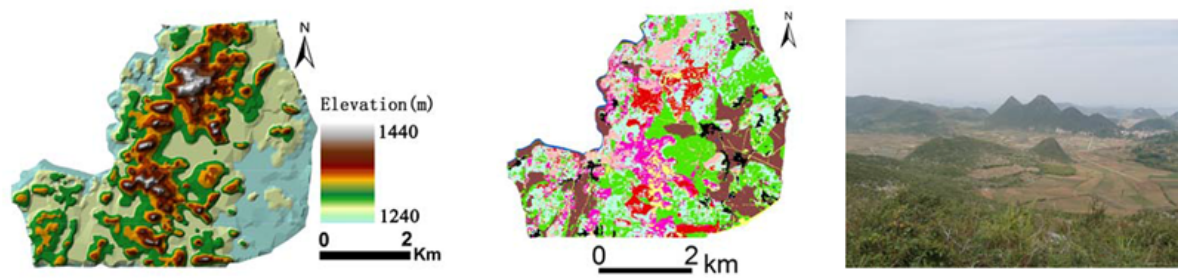

Open peak cluster-depression
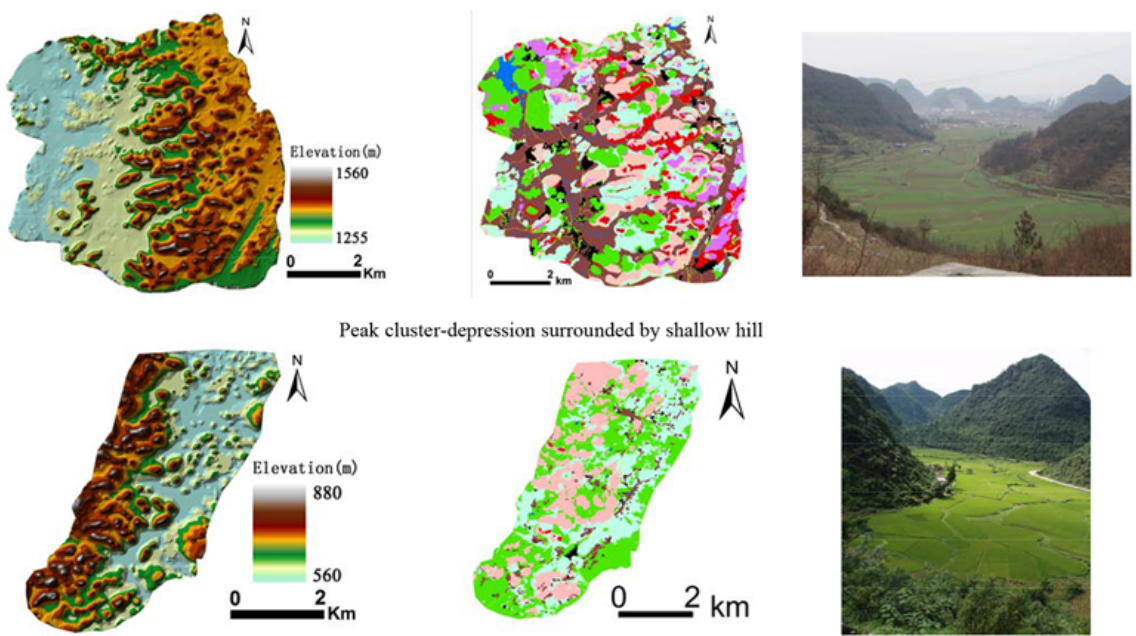

Peak cluster-depression surrounded by shallow hill

Topography
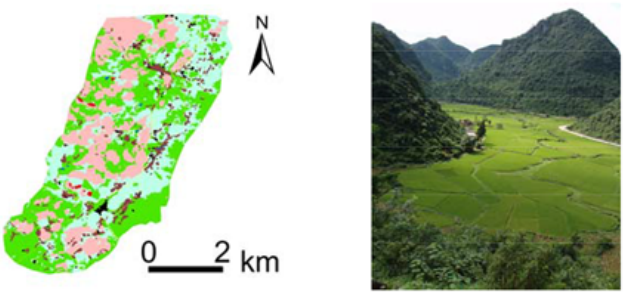

Shallow depressions
Land use and KRD

Cropland $\mathbf{E}$ Settlement $\quad$ Road $=$ Wate

Photos

\begin{tabular}{|c|c|c|c|c|c|c|}
\hline & & NKRD & PKRD & LKRD & MKRD & SKRD \\
\hline $\begin{array}{c}\begin{array}{c}\text { Exposure of baseme } \\
(\%)\end{array}\end{array}$ & rocks & $<10$ & $<30$ & $30-50$ & $50-70$ & $70-90$ \\
\hline $\begin{array}{l}\text { Characteristics of } \\
\text { image }\end{array}$ & ALOS & $\begin{array}{ll}\text { deep } & \text { red } \\
\text { patch } & \end{array}$ & $\begin{array}{l}\text { light } \\
\text { red }\end{array}$ & $\begin{array}{l}\text { shallow spot red, interspersed } \\
\text { grey }\end{array}$ & $\begin{array}{l}\text { shallow contiguous } \\
\text { grey }\end{array}$ & $\begin{array}{l}\text { contiguous grey and } \\
\text { white }\end{array}$ \\
\hline
\end{tabular}

Figure 2. The digital topography, land use and KRD of the study areas. 
Table 1. The characteristics of cropland patch in the study areas.

\begin{tabular}{lrrrrr}
\hline Land form & $\begin{array}{r}\text { Percentage } \\
\text { of flatland (\%) }\end{array}$ & $\begin{array}{r}\text { Largest patch } \\
\text { area }\left(\mathrm{hm}^{2}\right)\end{array}$ & $\begin{array}{r}\text { Smallest patch } \\
\text { area }\left(\mathrm{hm}^{2}\right)\end{array}$ & $\begin{array}{r}\text { Average patch } \\
\text { area }\left(\mathrm{hm}^{2}\right)\end{array}$ & $\begin{array}{r}\text { Aggregation } \\
\text { index of cropland }\end{array}$ \\
\hline $\begin{array}{l}\text { Peak-cluster canyon } \\
\begin{array}{l}\text { Continuous deep } \\
\text { depression }\end{array}\end{array}$ & 0.12 & 0.56 & 0.01 & 0.037 & 60.90 \\
$\begin{array}{l}\text { Shallow depression } \\
\begin{array}{l}\text { Peak-cluster depression- } \\
\text { valley combination }\end{array}\end{array}$ & 5.41 & 10.44 & 0.01 & 0.74 & 83.40 \\
$\begin{array}{l}\text { Open peak-cluster } \\
\text { depression }\end{array}$ & 5.94 & 9.84 & 0.02 & 0.55 & 82.06 \\
$\begin{array}{l}\text { Peak-cluster depression } \\
\text { surrounded by shallow hill }\end{array}$ & 10.74 & 241.68 & 0.06 & 3.36 & 92.67 \\
\hline
\end{tabular}

between 10 and $20 \mathrm{hm}^{2}$ accounting for $10.10 \%$ of the total cropland area in the continuous deep depressions. The cropland patches with sizes of $0.1-1 \mathrm{hm}^{2}$ are the most frequent at the shallow depressions areas in Dongtang. There are 37 patches of flat cropland, with a total area of $3.7 \mathrm{hm}^{2}$, and the largest patch area is up to $0.56 \mathrm{hm}^{2}$ in the peakcluster-canyon combination. In the peak-cluster depressions surrounded by shallow hill, the cropland patches between 20 and $50 \mathrm{hm}^{2}$ account for $35.11 \%$ of the total cropland area. The cropland patches between 20 and $50 \mathrm{hm}^{2}$ account for $39.68 \%$ of the total cropland area in the open peak-cluster depressions.

According to characteristics of cropland in different sizes and their aggregation, we categorize the cropland spatial distribution of the six study areas into two types as follows: (1) fragmented cropland, including the continuous deep depressions, shallow pond depressions, peak-cluster canyon, in which there are a great number of cropland patches, with mainly $0.1-1 \mathrm{hm}^{2}$, small and scattered cropland, accounting for a high proportion of the total cropland area; (2) centralized cropland, including peak-cluster depression-valley combination, peak-cluster depression surrounded by shallow hills and open peak-cluster depression. The cropland distribution of this type is relatively concentrated, and cropland patches with large sizes account for a high proportion of the total area.

\subsection{The relationships between cropland settlements and KRD in study area}

A significant negative correlation exists between the percentage of cropland area and the percentage of KRD area (Table 2); the correlation coefficient is 0.5394 . For continuous depressions, shallow depressions and peak-cluster canyon, the cropland accounts for less than $6 \%$ and the KRD area account for over $50 \%$. Cropland area in peak-cluster depression-valleys accounts for $10.74 \%$, but its settlement area exceeds $20.32 \%$, so the areas over LKRD account for $60 \%$. Cropland is relatively rich in peak-cluster depressions,
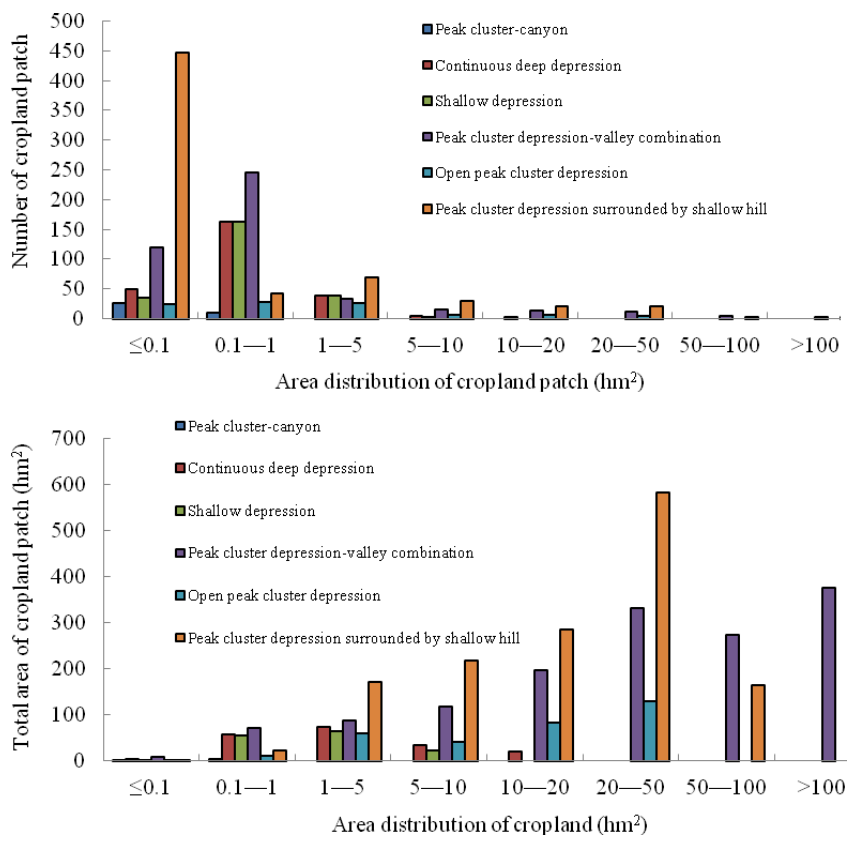

Figure 3. The distribution characteristics of cropland patches.

surrounded by shallow hills and open peak-cluster depressions. The area over LKRD accounts for $30 \%$, but the percentage of KRD area of open peak-cluster depressions is larger because of its higher ratio of settlement to cropland. Obviously, KRD is more serious for peak-cluster depressions with higher ratios of settlement area to cropland. The correlation coefficient between this ratio and KRD, MKRD and SKRD is $0.034,0.5125$ and 0.6824 respectively.

In order to reveal the corresponding relation between the change of cropland and the change of KRD around the settlements, furthermore, the settlements of the six study areas are taken as centers to build buffer belts with distances of 0 200, 200-400, 400-600, 600-800, 800-1000 and > $1000 \mathrm{~m}$. Then, the changes of cropland and KRD land percentage in buffer zones of the six study areas are compared. The results 
Table 2. Percentage of cropland, settlements and KRD desertified land (including light, moderate, severe KRD).

\begin{tabular}{lrrrrr}
\hline Land form & $\begin{array}{r}\text { Cropland } \\
(\%)\end{array}$ & $\begin{array}{r}\text { KRD } \\
(\%)\end{array}$ & $\begin{array}{r}\text { Settlement } \\
(\%)\end{array}$ & $\begin{array}{r}\text { Settlement/ } \\
\text { farmland }(\%)\end{array}$ & $\begin{array}{r}\text { Arable slope } \\
\text { land (\%) }\end{array}$ \\
\hline Shallow depression & 5.94 & 26.09 & 0.88 & 14.88 & 20.9 \\
Peak-cluster depression & 26.36 & 30.74 & 3.44 & 13.05 & 27.26 \\
surrounded by shallow hill & & & & & \\
$\begin{array}{l}\text { Open peak-cluster depression } \\
\text { Continuous deep }\end{array}$ & 15.51 & 31.25 & 3.37 & 21.74 & 10.84 \\
depression & 5.41 & 54.19 & 0.51 & 9.44 & 20.672 \\
$\begin{array}{l}\text { Cluster canyon } \\
\text { Peak-cluster depression- }\end{array}$ & 0.12 & 62.5 & 1.18 & 9801.04 & 12.06 \\
valley combination & 10.74 & 63.74 & 2.18 & 20.32 & 18.62 \\
\hline
\end{tabular}

show that the cropland decreases as the buffer distance increases. In areas within $400 \mathrm{~m}$ buffer distance, the cropland proportion in peak-cluster depressions surrounded by shallow hills is highest. The lowest is the peak-cluster canyon, and its cropland only distributes at this buffer range (Fig. 4). Correspondingly, the proportion of LKRD is highest within 200-400 m buffer distance, and reduces from peak-cluster canyon, continuous deep depressions, shallow depressions and peak-cluster depression valleys in turn.

The proportion of MKRD is highest within 200-400 and $0-200 \mathrm{~m}$ buffer distance, and the proportions of peakcluster depression-valleys and continuous deep depressions are higher than the other four study areas. This proportion of MKRD of shallow depression area is less than $0.1 \%$.

The highest proportion of SKRD is within 0-200, and then $200-400 \mathrm{~m}$ buffer distance at the peak-cluster canyon area. The relatively high proportion of SKRD of peak-cluster depression-valleys is within $0-800 \mathrm{~m}$; but at the open peakcluster depressions area, this SKRD proportion is relatively high in $800-1000 \mathrm{~m}$ buffer distance, where the slope land had been cultivated, now abandoned. The SKRD proportion within 200-400 $\mathrm{m}$ buffer distance at the continuous deep depressions is $0.44 \%$ and there is no SKRD in shallow depressions. What are the reasons for this phenomenon? We find that, in the karst mountains, the radius of cultivation is no more than $1000 \mathrm{~m}$. If the ratio of cropland surrounding settlements is lower, then, the slope reclamation, deforestation and other irrational disturbance is more severe, which also leads to more frequent occurrence of KRD.

\subsection{The process of KRD in peak-cluster depressions}

The analysis above shows that the KRD area and distribution is related to the quantity and distribution of cropland and settlement in the six study areas. Actually this relationship reflects human (settlements)-environment (cropland) interaction. Under the special human-environment relationship in karst peak-cluster depressions, these relationships reflect three scenarios of KRD processes.
1. The first scenario describes KRD with low land carrying capacity. Small cropland, small population, but population and arable land resources are at a low level of coordination, causing insignificant land degradation (KRD). Shallow depressions are an example of the first scenario. Cropland is small and population pressure exceeds land carrying capacity, which leads to mild or moderate degradation (mainly LKRD or MKRD). Continuous peak-cluster depression is typical in this scenario. The cropland is small, but population pressure exceeds land carrying capacity, causing land degradation (mainly SKRD and MKRD); Huajiang peak-clustervalley is such an example.

2. The second scenario describes KRD with moderate land carrying capacity. There are a large number of depressions and valleys but the population exceeds land carrying capacity. The use of sloping land for crops will cause more intense land degradation; the peak-cluster depression-valley combination is an example.

3. The third scenario describes KRD with high land carrying capacity. The Houzhaihe and Wangjiazhai areas are two examples. Cropland is larger because of continuous flatland or bigger depressions which can basically carry more population, so there are only a few slopes being used for crops at surrounding peak-clusters. Therefore, most of the land is degraded slightly; some is degraded severely.

\section{Discussions}

\subsection{A theoretical model of KRD formation}

The cropland resource pattern in peak-cluster depression areas is characterized by fertile land concentrated in depressions, and poor land or wasteland distributed on the peakcluster slopes around the depressions. Although some cropland aggregation effects exist, but not to a great extent, and the scale is small; therefore, the farming radius is still large 


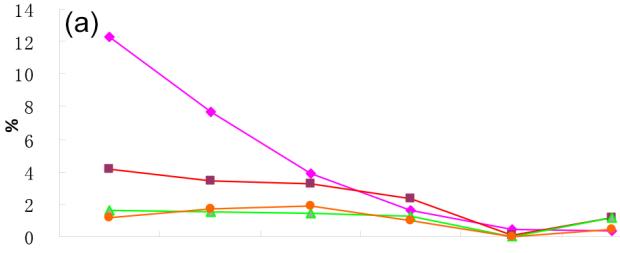

(c)
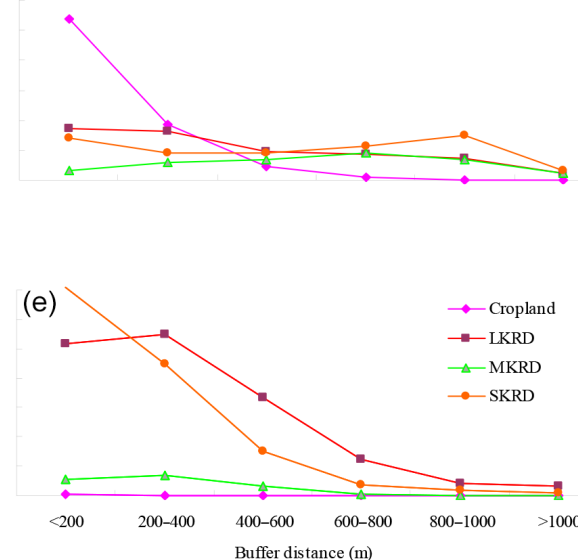

(b)

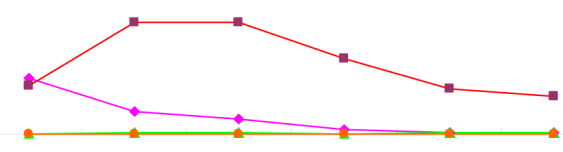

(d)

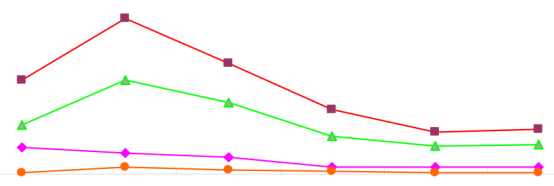

(f)

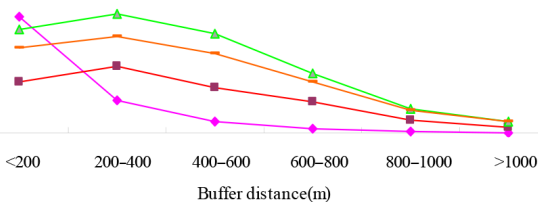

Figure 4. The proportions of cropland and KRD of different buffers accounting for the total area of the study area. (a) Peak-cluster depression surrounded by shallow hills. (b) Shallow depression. (c) Open peak-cluster depression. (d) Continuous deep depression. (e) Peak-cluster canyon. (f) Peak-cluster depression-valley combination.

in this area (Wu et al., 2007). Generally, the gentle farmland forms slightly desertified KRD landscapes; the steep land forms moderately desertified karst rocky landscapes due to slope soil erosion which makes KRD landscape degrade more seriously (Yang et al., 2006).

Based on the above analysis, the present study put forward a theoretical hypothesis: in the peak-cluster depression areas, the proportion of negative terrain (referring to depressions, often cultivated land resources) may determine population distribution, and the realistic population pressure (population density) may determine whether the peak-cluster depression areas will be degraded. We use the percentage of flat cropland of the total area to represent land bearing capacity and the ratio of settlement area to cropland area to represent population pressure. The formation of KRD in the peak-cluster depression areas can be clarified according to the variations of these two indexes (Fig. 5). As the percent of cropland decreases and the percent of settlement dedicated to the croplands increases, the severity of KRD increases. That is to say, the more serious rocky desertification KRD only occurs under the regions of low land carrying capacity and high population pressure where farmers have to take extreme steep reclamation activities. Thus, in the peak-cluster depression areas, low land carrying capacity is the fundamental cause of KRD. In general, the harmony between depression area (flat terrain) and population determines the ecological quality of peak-cluster depression areas.

\subsection{The significance of the theoretical model suggested in this paper to understand KRD}

In Europe, five main quality indices such as climate, vegetation, soils, groundwater and socioeconomic quality are used to estimate the sensitivity to land degradation and desertification (Symeonakis et al., 2014); therefore, the mixture of endogenous (manual agriculture, fuel wood and fodder extraction, land tenure and steep slopes) and exogenous drivers (high rainfall variability, climate change, prolonged drought or heavy rainfall) must be taken into account in the process of combating desertification (De Pina Tavares et al., 2014). Moreover, changing governance and transition towards new political and economic structures have played a key role in shaping today's land degradation in the context of climatic variability (Stringer and Harris, 2014). The eco-environment of karst mountains is fragile and the land degradation is mainly driven by desertification processes. Generally speaking, lithology and soil type and road influence are identified as the leading factors influencing KRD (Xu and Zhang, 2014; Yang et al., 2013). The succession of KRD has had different impacts on soil fertility indicators (Xie et al., 2015); i.e., the genesis of KRD has been attributed to land mismanagement of local households (Wu et al., 2011) and it has been found that climate change accelerates rocky desertification in the karst areas (Xiong et al., 2009). However, it has not been clarified why the local farmers take land mismanage- 


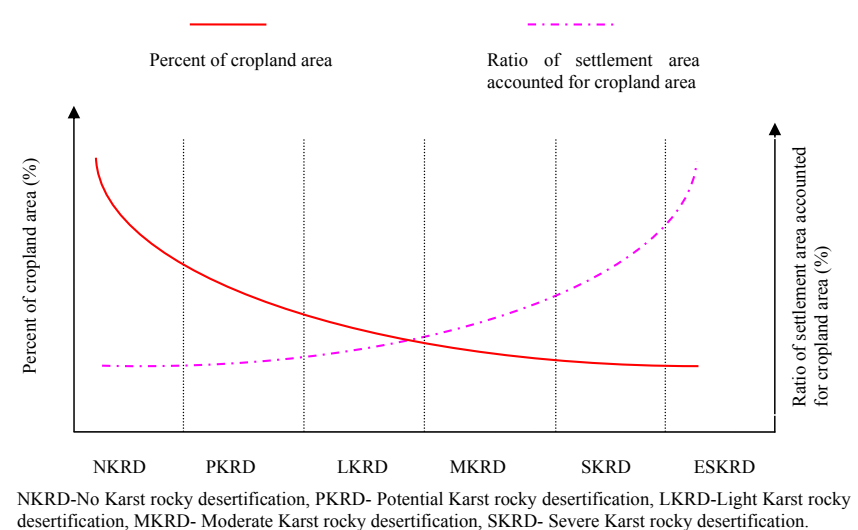

desertification, MKRD- Moderate Karst rocky desertification, SKRD- Severe Karst rocky desertification.

Figure 5. The theoretical formation models of KRD in the peakcluster depression areas.

ment (Yan and Cai, 2015). The relationships of settlements, cropland and KRD processes at six different peak-cluster depression combination areas are compared. Serious rocky desertification is found in areas with less cultivated land with a slope $<6^{\circ}$, low land carrying capacity and big population pressure. This phenomenon confirms that the theoretical assumptions we proposed are correct. Therefore, we can assume that the main reason for KRD is population exceeding land carrying capacity in karst mountains of Southwest China; that is to say, low land carrying capacity leads to the conversion of sloping land into croplands, and this is the main driving factor leading to KRD (Ying et al., 2014). KRD is a kind of land degradation that occurs in vulnerable karst dryland socioecological systems (Bisaro et al., 2014; Yang et al., 2011). The nature of KRD in karst mountains is evident by low land carrying capacity and high population pressure.

The correlations between cropland richness, land carrying capacity and KRD can reasonably explain the occurrence of KRD at different scales. This paper can help reveal the cause of KRD formation. Additionally, this paper also pointed out the prevention and control measures of KRD, including increasing land carrying capacity or decreasing population. Revegetation alone is difficult to increase land carrying capacity, but decreasing population in the short term is also difficult, so increasing land carrying capacity is the primary means of controlling KRD.

\subsection{Some insufficiencies}

1. The inadequacy of the analysis of the ratio of settlement to cropland is a disadvantage. Although studies show that the spatial distribution of settlements can replace population distribution (Niu et al., 2006), the shortcoming of this paper is the use of the settlement area only. Due to some settlements being abandoned in recent years, the changes of settlements and population may not be exactly the same. Therefore, further research should combine the evolution of the population and the livelihoods of farmers to calculate the land carrying capacity. Meanwhile, whether adjacent depressions of settlements are cultivated by farmers was not taken fully into account in some locations; this necessitates further field investigations.

2. The genesis of KRD according to land use in karst mountains is the degradation of forestland into shrub grassland due to deforestation, then finally, degradation into weed slopes by repeated disturbances. The forest turns into slope cropland through deforestation, and then, experiences KRD through water and soil loss. This paper analyzes the nature of KRD from the perspective of land carrying capacity, but does not discuss other factors such as deforestation.

3. This paper reveals the mechanisms of KRD of peakcluster depressions by using the number of croplands to represent the land carrying capacity and the settlements to find out the population pressure. Subsequent studies should consider the index of smallest cropland per capita and cropland pressure (Cai et al., 2002), so as to further explore the mechanisms and processes of the human-environment relationship of peak-cluster depressions.

\section{Conclusions}

The current studies do not discuss the occurrence and development of KRD from the perspective of cropland, settlement population and its corresponding ecological impact. This paper works from the assumptions about KRD in peak-cluster depressions based on previous studies, and selects six typical peak-cluster depression areas in the province of Guizhou to conduct case studies for this theoretical assumption. Some views have been concluded as follows.

1. The KRD area and distribution is related to the quantity and distribution of cropland and settlements in the six study areas. KRD is a kind of response to this interacting relationship between humans (settlements) and the environment (cropland).

2. SKRD only happened in areas with low land carrying capacity and large population pressure.

3. The characteristics of KRD are as follows. (1) Population pressure exceeds land carrying capacity. (2) A lack of arable depression resources makes slope land arable. (3) Low land carrying capacity is the root cause of karst rocky desertification.

Acknowledgements. This research was supported by the National Natural Science Foundation of China (41261045) and the National Key Technology R \& D Program (2014BAB03B02). We thank the 
editor and two anonymous reviewers for their valuable comments and suggestions that helped improve the manuscript.

Edited by: A. Cerdà

\section{References}

Bisaro, A., Kirk, M., Zdruli, P., and Zimmermann, W.: Global drivers setting desertification research priorities: Insights from a stakeholder consultation forum, Land Degrad. Dev., 25, 5-16, 2014.

Bou, K. R., Abdallaha, C., and Khawlie, M.: Assessing soil erosion in Mediterranean karst landscapes of Lebanon using remote sensing and GIS, Eng. Geol., 99, 239-254, 2008.

Cai, Y. L., Fu, Z. Q., and Dai, E. F.: The minimum area per capita of cultivated land and its implication for the optimization of land resource allocation, Acta Geographica Sinica, 57, 127-134, 2002 (in Chinese).

De Pina Tavares, J., Ferreira, A. J. D., Reis, E. A., Baptista, I., Amoros, R., Costa, L., Furtado, A. M., and Coelho, C.: Appraising and selecting strategies to combat and mitigate desertification based on stakeholder knowledge and global best practices in cape verde archipelago, Land Degrad. Dev., 25, 45-57, 2014.

Gabrovšek, F., Knez, M., Kogovšek, J., Mihevc, A., Mulec, J., Perne, M., Pipan, T., Prelovšek, M., Slabe, T., Šebela, S., and Ravbar, N.: Development challenges in karst regions: sustainable land use planning in the karst of Slovenia, Carbonates Evaporites, 26, 365-380, 2011.

Gams, I.: Origin of the term "karst", and the transformation of the Classical Karst (kras), Environ. Geol., 21, 110-114, 1993.

Guo, F., Jiang, G. H., Yuan, D. X., and Polk, J. S.: Evolution of major environmental geological problems in karst areas of Southwestern China, Environ. Earth Sci., 69, 2427-2435, 2013.

Huang, Q. H. and Cai, Y. L.: Spatial pattern of Karst rock desertification in the Middle of Guizhou Province, Southwestern China, Environ. Geol., 52, 1325-1330, 2007.

Izzo, M., Araujo, N., Aucelli, P. P. C., Maratea, A., and Sánchez, A.: Land sensitivity to desertification in the Dominican Republic: an adaptation of the ESA methodology, Land Degrad. Dev., 24, 486-498, 2013.

Jiang, Y. J., Li, L. L., Groves, C., Yuan, D. X., and Kambesis, P.: Relationships between rocky desertification and spatial pattern of land use in typical karst area, Southwest China, Environ. Earth Sci., 59, 881-890, 2009.

Jiang, Z. C., Li, X. K., and Zeng, F. P.: Ecological rehabilitation in Karst fengcong depression, Beijing, Geology Press, 1-11, 2007 (in Chinese).

Jiang, Z. C., Lian, Y. Q., and Qin, X. Q.: Rocky desertification in Southwest China: impacts, causes, and restoration, Earth Sci. Rev., 132, 1-12, 2014.

Kaligarič, M. and Ivajnšič, D.: Vanishing landscape of the "classic" Karst: changed landscape identity and projections for the future, Landscape Urban Plan., 132, 148-158, 2014.

Le Houérou, H. N.: Bioclimatology and biogeography of Africa, Springer-Verlag: Berlin and Heidelberg, 2009.

Li, X. K., Lv, S. H., Jiang, Z. C., He, C. X., Lu, S. H., Xiang, W. S., and OU, Z. L.: Experiment on vegetation rehabilitation and optimization of agro-forestry system in karst fengcong depres- sion (Peak Cluster) area in Western Guangxi, China, Journal of Natural Resources, 20, 92-98, 2005 (in Chinese).

Li, Y. B., Shao, J. A., Yang, H., and Bai, X. Y.: The relations between land use and karst rocky desertification in a typical karst area, China, Environ. Geol., 57, 621-627, 2009.

Li, Y. B., Xie, J., Luo, G. J., Yang, H., and Wang, S. J.: The evolution of a Karst rocky desertification land ecosystem and its driving forces in the Houzhaihe area, China, Open Journal of Ecology, 5, 501-512, 2015.

Miao, L., Moore, J. C., Zeng, F., Lei, J., Ding, J., He B., and Cui, $\mathrm{X}$.: Footprint of research in desertification management in China, Land Degrad. Dev., 26, 450-457, 2015.

Niu, S. W., Liu, Z. G., Guo, X. D., Li, G. Z., and Wang, Z. F.: Population distribution characteristics and pattern on hill and mountainous region basing on village scale, J. Mt. Sci., 24, 684-691, 2006.

North, L. A., Beynen, P. E.V., and Parise, M.: Interregional comparison of karst disturbance: West-central Florida and southeast Italy, J. Environ. Manage., 90, 1770-1781, 2009.

Peng, W. X., Song, T. Q., Zeng, F. P., Wang, K. L., Du, H., and Lu, S. Y.: Models of vegetation and soil coupling coordinative degree in grain for green project in depressions between karst hills, Transactions of the Chinese Society of Agricultural Engineering, 27, 305-310, 2011 (in Chinese).

Praiser, M. and Pascali, V.: Surface and subsurface environmental degradation in the karst of Apulia, southern Italy, Environ. Geol., 44, 247-256, 2003.

Sauro, U.: Human impact on the karst of the Venetian Fore-Alps, Italy, Environ. Geol., 21, 115-121, 1993.

Stringer, L. C. and Harris, A.: Land degradation in Dolj County, Southern Romania: Environmental changes, impacts and responses, Land Degrad. Dev., 25, 17-28, 2014.

Symeonakis, E., Karathanasis, N., Koukoulas, S., and Panagopoulos, G.: Monitoring sensitivity to land degradation and desertification with the environmentally sensitive area index: The case of lesvos island, Land Degrad. Dev., doi:10.1002/ldr.2285, 2014.

Torres, L., Abraham, E. M., Rubio, C., Barbero, C., and Ruiz, M.: Desertification research in Argentina, Land Degrad. Dev., 26, 433-440, 2015.

UNCCD (United Nations Convention to Combat Desertification): United nations convention to combat desertification in those countries experiencing serious drought and/or desertification particularly in Africa: Text with annexes, UNEP, Nairobi, 1994.

Wang, S. J., Liu, Q., M., and Zhang, D. F..: Karst Rock Desertification in Southwestern China: Geomorphology, land use, impact and rehablitation, Land Degrad. Dev., 15, 115-121, 2004a.

Wang, S. J., Li, R. L., and Sun, C. X.: How Types of carbonate assemblages constrain the distribution of karst rocky desertification in Guizhou Province, P. R. China: phenomena and mechanism, Land Degrad. Dev., 15, 123-131, 2004b.

Wang, X., Ma, W. Y., Lang, L. L., and Hua, T.: Controls on desertification during the early twenty-first century in the Water Tower region of China, Reg. Environ. Change, 15, 735-746, 2015.

Wu, L. L., Zhou Y. Z., Chen, Z. S., Song, S. Q., Lu, Y., and Zhou, H. J.: Analysis on scaled potential of land resources of karst mountain areas based on GIS technology and landscape ecology methods, Areal Res. Develop., 26, 112-116, 2007 (in chinese).

Wu, X. Q., Liu, H. M., Huang, X. L., and Zhou, T.: Human Driving Forces: Analysis of rocky desertification in karst region in Guan- 
ling County, Guizhou Province, Chinese Geographical Science, 21, 600-60, 2011.

Xie, L. W., Zhong, J., Chen, F. F., Cao, F. X., Li, J. J., and Wu, L. C.: Evaluation of soil fertility in the succession of karst rocky desertification using principal component analysis, Solid Earth, 6, 515-524, doi:10.5194/se-6-515-2015, 2015.

Xiong, Y. J., Qiu, G. Y., Mo, D. K., Lin, H., Sun, H., Wang, Q. X., Zhao, X. H., and Yin, J.: Rocky desertification and its causes in karst areas: a case study in Yongshun County, Hunan Province, China, Environ. Geol., 59, 1481-1488, 2009.

$\mathrm{Xu}$, E. Q. and Zhang, H. Q.: Characterization and interaction of driving factors in karst rocky desertification: a case study from Changshun, China, Solid Earth, 5, 1329-1340, doi:10.5194/se5-1329-2014, 2014.

Xu, E. Q., Zhang, H. Q., and Li, M. X.: Mining spatial information to investigate the evolution of karst rocky desertification and its human driving forces in Changshun, China, Sci. Total Environ., 458-460, 419-426, 2013.

Yan, X. and Cai, Y. L.: Multi-scale anthropogenic driving forces of Karst rocky desertification in Southwest China, Land Degrad. Dev., 26, 193-200, 2015.

Yang, Q. Q., Wang, K. L., Zhang, C. H., Yue, Y. M., Tian, R. C., and Fan, F. D.: Spatio-temporal evolution of rocky desertification and its driving forces in karst areas of Northwestern Guangxi, China, Environ Earth Sci., 64, 383-393, 2011.

Yang, Q. Y., Jiang, Z. C., Ma, Z. L., Luo, W. Q., Xie, Y. Q., and Cao, J. H.: Relationship between karst rocky desertification and its distance to roadways in a typical karst area of Southwest China, Environ Earth Sci., 70, 295-302, 2013.
Yang, Z. S., Liu, Y. S., Bao, G. J., Li, Z. G., and He, Y. M.: Rehabilitation and sustainable use pattern of rocky-desertified land in Southwest China's poverty-stricken karst mountainous areas - a case study in Benggu Township, Xichou County, Yunnan, China, J. Mountain Sci., 3, 237-246, 2006.

Ying, B., Xiao, S. Z., Xiong, K. N., Cheng, Q. W., and Luo, J. S.: Comparative studies of the distribution characteristics of rocky desertification and land use/land cover classes in typical areas of Guizhou province, China, Environ. Earth Sci., 71, 631-645, 2014.

Yuan, D. X.: Rock desertification in the subtropical karst of south China, Z. Geomorphol., 108, 81-90, 1997

Yue, Y. Y., Zhang, B., Wang, K. L., Liu, B., Li, R., Jiao, Q. J., Yang, Q. Q., and Zhang M. Y.: Spectral indices for estimating ecological indicators of karst rocky desertification, Int. J. Remote Sens., 31, 2115-2122, 2010.

Zhang, D. F., Wang, S. J., Zhou, D. Q., and Li, R. L.: Intrinsic driving mechanism of land rocky desertification in karst regions of Guizhou Province, B. Soil Water Conserv., 21, 1-5, 2001 (in Chinese).

Zhang, X., Shang, K., Cen, Y., Shuai, T., and Sun, Y. L.: Estimating ecological indicators of karst rocky desertification by linear spectral unmixing method, International Journal of Applied Earth Observation and Geoinformation, 31, 86-94, 2014. 